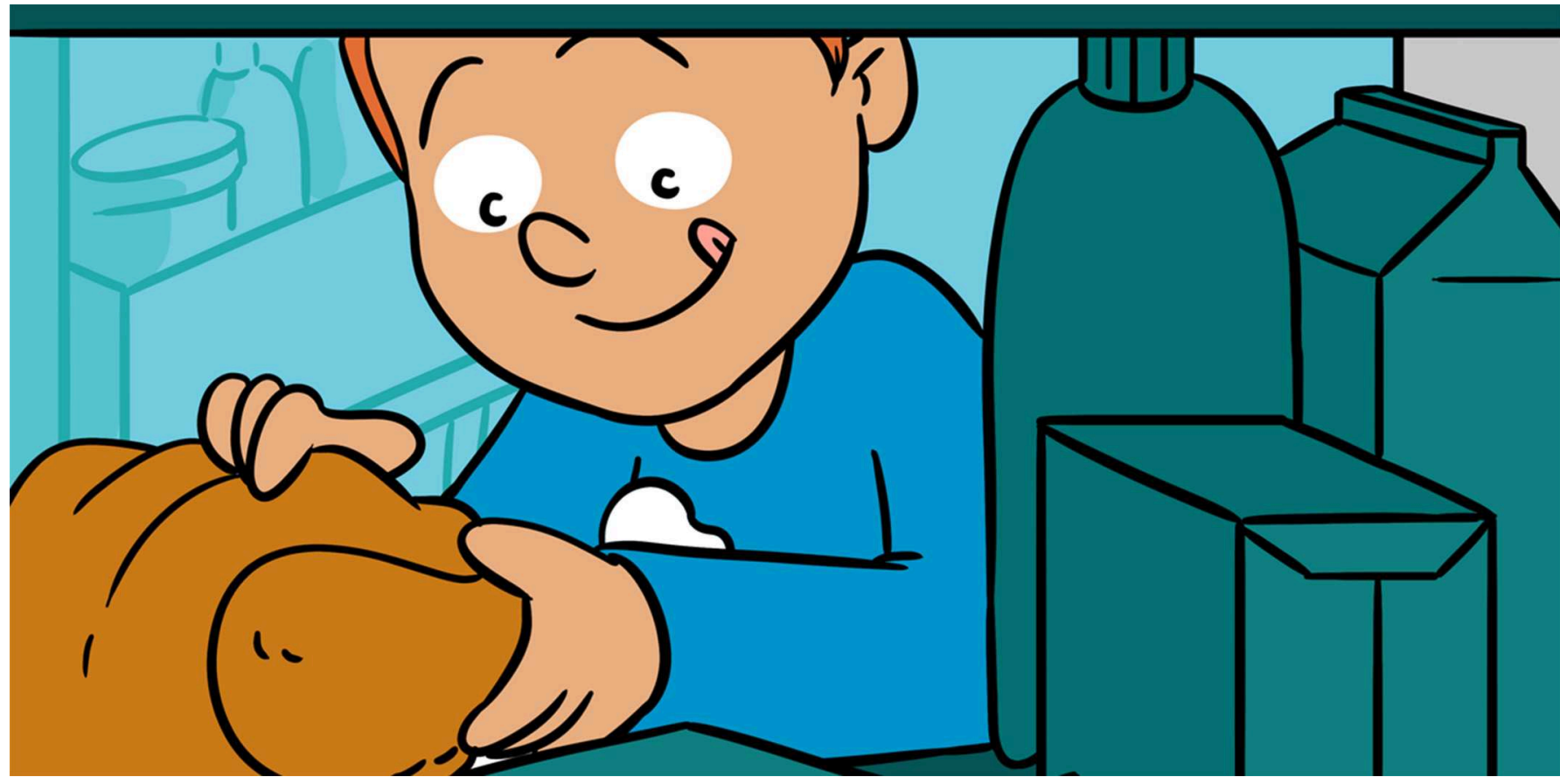

\title{
HOW STRESS CAN (SOMETIMES) MAKE US EAT MORE
}

\section{Sarah J. Spencer *}

School of Health and Biomedical Sciences and ARC Centre of Excellence for Nanoscale Biophotonics, RMIT University, Melbourne, VIC, Australia

YOUNG REVIEWERS: EXPLORA SCIENCE

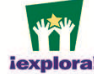
iexplora! CENTER AND CHILDREN'S MUSEUM AGES: 8-14
What happens to your appetite when you are stressed? Do you reach straight for the ice cream and chips? Well, many of us do. With increasing stress in all of our lives, this pattern of stress-related eating can lead to excess weight gain and a higher risk of obesity. But why do we tend to overeat when stressed? One of the biggest culprits may be a hormone called cortisol. Cortisol can stimulate the appetite and make yummy foods seem even yummier. This article discusses how responding to stress is an important part of our normal lives, but how long-lasting stress can make us overeat and gain weight. Knowing about how stress can make us overeat is important in helping us make healthy food choices.

What happens to your appetite when you are stressed or worried? Do you get super hungry for cookies and ice cream? Or does your gut get all fluttery and you do not want to eat at all? Many of us overeat when we are stressed; and if we are very stressed, or stressed for a very long time, this can lead to weight problems in the long-term. But how does stress make us want to eat? 
Figure 1

What happens when we are stressed? When we encounter something stressful (like a T. Rex) the sympathetic nervous system is activated, leading to the quick release of adrenaline from the adrenal gland (located on top of each kidney, as shown in the left image). Adrenaline acts on the heart, lungs, and muscles to increase heart rate, breathing, and blood flow. A matter of minutes after this, the endocrine system is also activated.

Endocrine system activation suppresses appetite and causes the adrenal gland to release cortisol. Cortisol acts at the brain to heighten memory and the immune system and reduces stress levels back to normal. Images are adapted from Servier Medical Art, which is licensed under a Creative Commons Attribution 3.0 Unported License https://creativecommons. org/licenses/by/3.0/.

SYMPATHETIC

NERVOUS SYSTEM

("SIM-PA-THE-TIC NER-VUS SIS-TEM")

A part of the nervous system that accelerates the heart rate, constricts blood vessels, and raises blood pressure.

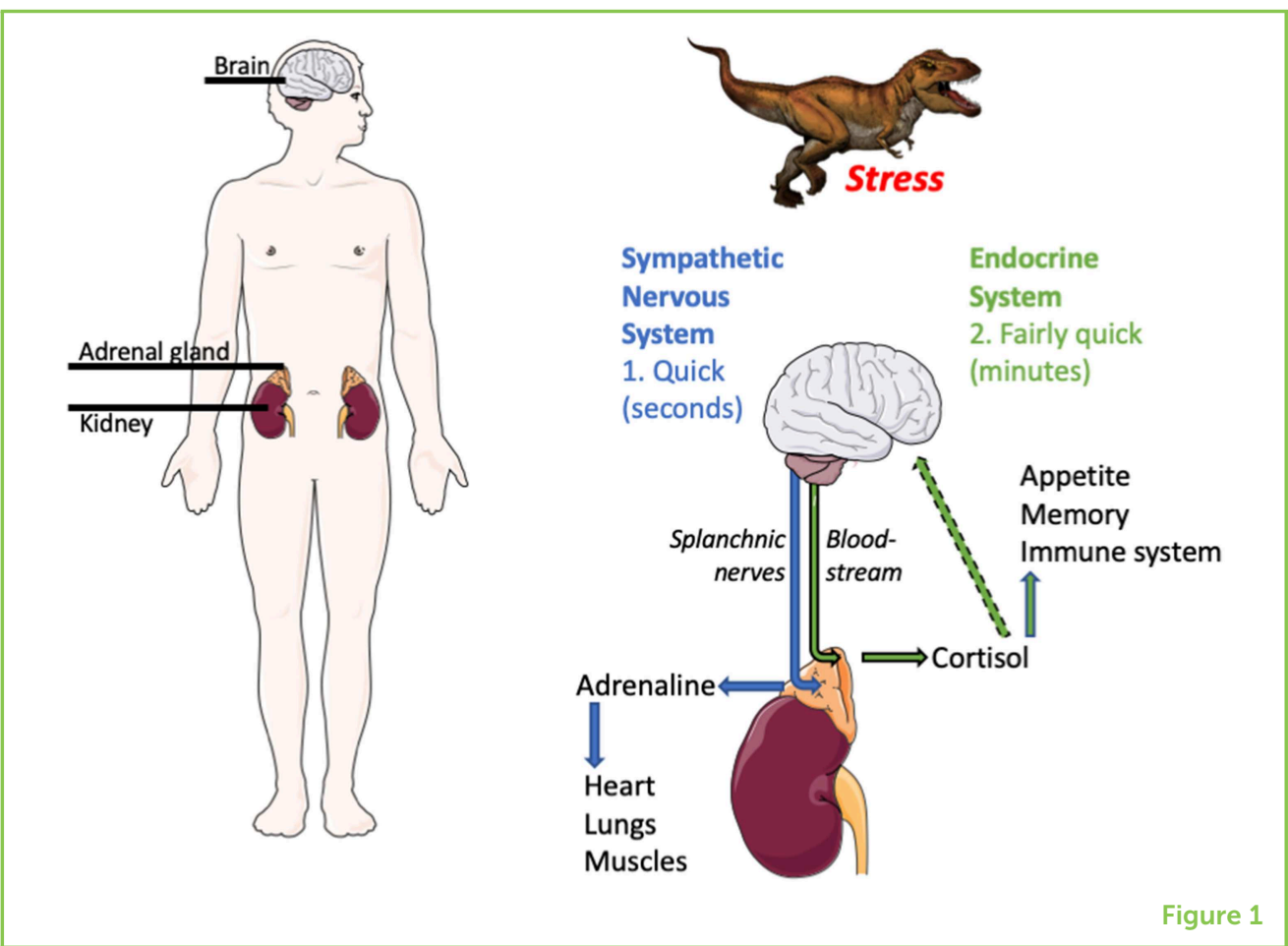

\section{WHAT IS STRESS?}

We all know that feeling of being overwhelmed, out of control, heart racing, scared. In the body these feelings come from two systems [1]. First, the sympathetic nervous system sends a hormone called adrenaline pumping around your blood stream. This hormone increases your heart rate and makes you feel like running away or turning around and fighting. Second, the endocrine system sends a different set of hormones, including one called cortisol, into your bloodstream and this helps you deal with the stress (Figure 1).

Imagine you are walking down the street. You turn a corner and there is a great big hungry Tyrannosaurus Rex sitting there. What happens? First, your sympathetic nervous system, which is a part of the nervous system that accelerates the heart rate, constricts blood vessels, and raises blood pressure, immediately gets activated. Adrenaline is pumped into your blood. Your heart beats faster, your breathing increases, your blood gets shunted to your muscles. You run away.

As this is happening, cortisol increases in your blood, too. Activation of the endocrine system, which is the glands in the body that make hormones for helping the body deal with all its functions, quickly suppresses appetite-you do not want to be reaching for your snacks with a T. Rex breathing down your neck. Cortisol also does things like heighten memory. This can be useful to ensure you avoid similar stressful dinosaurs in future. And cortisol feeds back onto the brain, to shut off the stress response, so that your appetite, memory, and 
HORMONE

("HOR-MOAN")

A substance released from one organ in the body that travels to another organ and tells it what to do.

\section{ADRENALINE}

("AD-REN'AL-IN")

A stress hormone released that acts on the heart, lungs, and muscles to increase heart rate, breathing, and blood flow.

\section{ENDOCRINE}

SYSTEM

("EN-DO-CRY-N

SIS-TEM")

The glands in the body that make hormones for helping the body deal with all its functions, including stress.

\section{CORTISOL} ("KOR-TI-ZOL")

A hormone that orchestrates the response to stress and helps the body deal with the stressful event. cortisol itself come back to normal when the stressful situation is over.

\section{RESPONDING TO STRESS IS GOOD....AND BAD...}

Responding to stress in the way described above is a very positive thing. In fact, it is essential. Without a stress response, the T. Rex would probably eat us. But, when you think about it, how many times in most of our lives are we stressed because a T. Rex (or any predator, for that matter) is going to eat us? We are much more likely to be stressed by ongoing non-physical worries. Social relationships, performance in school or at work, the unknown of trying something new; these are the things that are likely to stress us on a daily basis. These are also situations in which an increased heart rate or more blood flow to your muscles are not particularly useful at all. In these cases, known as chronic stress (because it lasts for a long time), the stress response can actually be very bad for you.

\section{WHAT DOES CHRONIC STRESS DO TO APPETITE?}

Chronic stress can have lots of negative effects. It can lead to anxiety and depression, memory loss, heart problems, and many others. In this article, we are going to focus on the way chronic stress can affect appetite and weight [2].

I have already mentioned that acute stress, like when you are escaping from the T. Rex, leads to appetite suppression. This is true, but only in the short term. Once appetite is reduced by stress, cortisol has a secondary role to increase appetite again. In the case of the dinosaur, this makes sense. You have just spent a lot of energy running away from a predator. Part of cortisol's role is to get you to replace that energy by eating more than usual. But, if you are stressed because there is an exam coming up and you forgot to study, an extra tub of ice cream is not going to help anything. If cortisol is elevated all the time by ongoing stress, so is this drive to eat.

Cortisol also encourages us to store energy from food as fat. Basically, this is stockpiling energy in case of a future need (like running away from future predators). Again, this is not so useful if the source of the stress is not going to physically affect us. When we are chronically stressed and cortisol is increased all the time, we not only overeat but also store more of that energy as fat, without necessarily engaging in extra physical activity to counter the weight gain that results.

Together, this means that the more chronically stressed you are, the more likely you are to eat too much, gain weight, and eventually end up obese. It is also really important to note that obesity and poor diet 
Figure 2

How does cortisol increase appetite? (A) When we are not stressed, ghrelin stimulates appetite and leptin inhibits appetite by acting on the hypothalamus. (B) Chronic stress, leading to excess cortisol, can stimulate ghrelin, enhancing appetite, and eating. Chronic excess cortisol can also reduce the sensitivity of the hypothalamus to leptin, again enhancing appetite and eating. Images are adapted from Servier Medical Art, which is licensed under a Creative Commons Attribution 3.0 Unported License https://creativecommons. org/licenses/by/3.0/.

HYPOTHALAMUS ("HIE-PO-THAL-AMUS")

A brain region that is responsible for controlling feeding (and some other important things).

\section{LEPTIN ("LEP-TIN")}

A hormone that tells the brain to stop eating

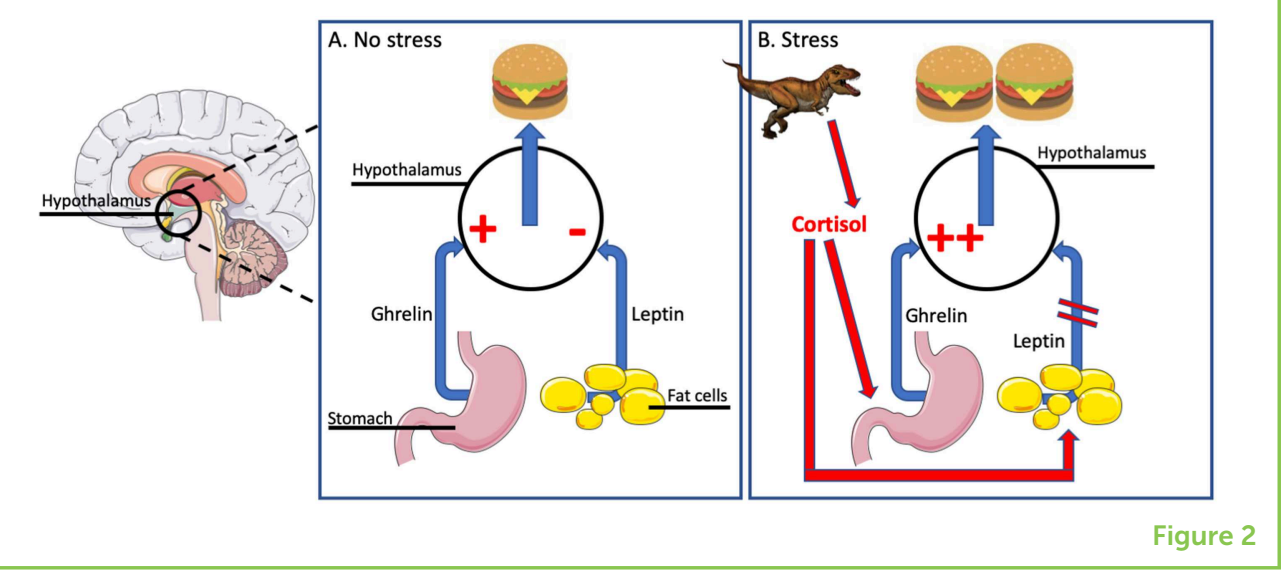

can, themselves, lead to increased responses to stress. This means that the cycle of stress-eating-stress can be very hard to break [2].

\section{HOW DOES CORTISOL INCREASE APPETITE AND WEIGHT?}

Cortisol increases appetite and weight in several ways [2]. These mainly involve the hypothalamus. The hypothalamus is a region of the brain that regulates many of the ways we interact with the world. For example, it regulates the stress response (including stimulating the release of cortisol into the bloodstream). It controls the balance of our reproductive hormones, and it also controls how much we eat. When too much cortisol circulates in the bloodstream for a long time, this cortisol increases the activity of neurons in the hypothalamus that signal "I am hungry" to the rest of the brain (Figure 2). When you are stressed, the brain can actually think you are hungrier-even when your need for energy has not changed.

Cortisol also reduces the sensitivity of the hypothalamus to another hormone, leptin. Leptin normally signals "stop eating, I am full." When there is a lot of cortisol around for a long time, leptin is less able to send this signal and so this "I am full" message is no longer as powerful.

Cortisol can even interfere with other hormones that change how rewarding and yummy we find food. It can increase our preference for "comfort food"-foods that are high in energy, such as those that contain lots of fat and sugar [3].

As mentioned, cortisol can also encourage weight gain by telling the body to store energy as fat. Even if a stressed person resists all the extra brain signals telling him or her to eat more, the person may still put on weight because the body changes the way it processes food. Cortisol encourages fat storage in part by stimulating fat cells to grow and mature, particularly in the fat around the stomach. This is a pattern of fat distribution that not only gives a person a big belly but can also contribute to heart disease. 


\section{WHY DOES NOT EVERYONE OVEREAT WITH STRESS?}

Having said all of this about how cortisol encourages us to eat, store fat, and gain weight, we know this does not happen to everyone. Some people eat a lot less and lose a lot of weight with chronic stress. So, what is going on?

First, males and females respond differently to stress. For instance, women have higher cortisol responses to social stress challenges, like rejection by their friends, while men tend to have higher responses to achievement-based challenges, like mathematical tests. People are more likely to overeat when they have high cortisol in response to a stressful situation. This means that women are more likely to overeat if the stress is something social, while men are more likely to overeat if the stressful event is achievement-based. Unfortunately for the guys, males are more likely to increase fat storage around the belly when they are chronically stressed.

Second, many individual factors can influence the response stress. For instance, my group has shown that stress or poor diet early in life, when the hypothalamus is still developing, can lead to excessive sensitivity to stress later in life [4]. If individuals have early exposure to chronic stress, they may be more likely to have chronically high cortisol, even if nothing stressful is happening. Also, the brains of these individuals may not respond to cortisol properly, so cortisol can be less effective at shutting of the stress response. This means that, even though many of us are exposed to the same type of stress in our daily lives, some people will respond by increasing their cortisol levels in a lasting way while others will not.

People who overeat with chronic stress have sometimes been classified by science as "emotional eaters." These can be compared with "non-emotional eaters," who do not change their eating habits after stress [5]. Science has shown that emotional and non-emotional eaters have important differences in another crucial stress and appetite hormone, ghrelin. Ghrelin normally signals to the hypothalamus when it is time to eat. Ghrelin is therefore thought of as the "hunger hormone" and it promotes appetite. It is really interesting, then, that ghrelin increases in the blood when someone is stressed. It is even more interesting that, if there is food to eat, ghrelin will come back to normal very quickly in non-emotional eaters but stays high in emotional eaters. This persistently high ghrelin means a persistent hunger signal in emotional eaters [5].

\section{WHAT CAN WE DO?}

So, is there anything we can do to avoid stress-related over-eating? Well, we cannot eliminate all stress from our lives. Often, the very things we find stressful are those that challenge us to grow. And 
we cannot eliminate our stress response. We need it-not just in case we encounter a hungry dinosaur, but also for more likely threats. However, we may be able to manage both the sources of chronic stress and our responses to them. For instance, maintaining positive social relationships with friends and parents is a very good stress-management strategy and can reduce the responses to stressful situations. Developing self-reliance and optimism, as well as engaging in demanding activities like sports, making music, or playing tricky games, has also been shown to reduce stress responses. In addition, understanding why we want to eat that tub of ice cream in the first place could help us make healthy food choices. In the meantime, science is working on treatments, for both obesity and excessive stress responses that will hopefully prove useful in the future.

\section{REFERENCES}

1. Sapolsky, R. M. 1996. Why stress is bad for your brain. Science 273:749-50.

2. Spencer, S. J., and Tilbrook, A. 2011. The glucocorticoid contribution to obesity. Stress 14:233-46. doi: 10.3109/10253890.2010.534831

3. Tomiyama, A. J., Dallman, M. F., and Epel, E. S. 2011. Comfort food is comforting to those most stressed: evidence of the chronic stress response network in high stress women. Psychoneuroendocrinology 36:1513-9.

doi: 10.1016/j.psyneuen.2011.04.005

4. Sominsky, L., Ziko, I., and Spencer, S. J. 2017. Neonatal overfeeding disrupts pituitary ghrelin signalling in female rats long-term; Implications for the stress response. PLOS ONE 12:e0173498. doi: 10.1371/journal.pone.0173498

5. Raspopow, K., Abizaid, A., Matheson, K., and Anisman, H. 2014. Anticipation of a psychosocial stressor differentially influences ghrelin, cortisol and food intake among emotional and non-emotional eaters. Appetite 74:35-43.

doi: 10.1016/j.appet.2013.11.018

SUBMITTED: 25 March 2019; ACCEPTED: 25 June 2019;

PUBLISHED ONLINE: 11 July 2019.

EDITED BY: Kathleen Y. Haaland, University of New Mexico, United States

CITATION: Spencer SJ (2019) How Stress Can (Sometimes) Make Us Eat More. Front. Young Minds 7:95. doi: 10.3389/frym.2019.00095

CONFLICT OF INTEREST STATEMENT: The author declares that the research was conducted in the absence of any commercial or financial relationships that could be construed as a potential conflict of interest.

COPYRIGHT @ 2019 Spencer. This is an open-access article distributed under the terms of the Creative Commons Attribution License (CC BY). The use, distribution or reproduction in other forums is permitted, provided the original author(s) and the copyright owner(s) are credited and that the original publication in this journal is cited, in accordance with accepted academic practice. No use, distribution or reproduction is permitted which does not comply with these terms. 


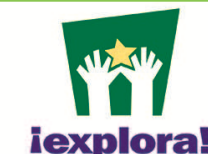

Ideas You Can Touch Ideas que puedes tocar

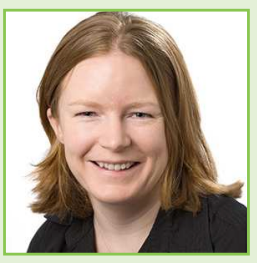

\section{YOUNG REVIEWERS}

\section{EXPLORA SCIENCE CENTER AND CHILDREN'S MUSEUM, AGES: 8-14}

The Explora Young Minds reviewers are a group of science enthusiasts working with museum educators and mentors from the University of New Mexico. We enjoy learning about the brain through the articles. We also enjoy asking questions and making suggestions to help the scientists make their work more understandable for everyone! We were helped by our Science Mentor Jennifer Walter. She just received her Ph.D. in Pediatric Neuropsychology. She enjoys working with kids, playing with her dog, and trying to cook new recipes.

\section{AUTHOR}

\section{SARAH J. SPENCER}

I am an Associate Professor and Researcher at RMIT University in Melbourne, Australia. I study how the brain's immune system responds to different challenges, like stress and diet. I have worked as a Scientist in New Zealand, Canada, and Australia and I love how being a scientist gives me opportunities to travel and meet lots of inspiring people. I have two wonderful children who keep me busy at home. *sarah.spencer@rmit.edu.au 